\title{
Modeling Fire Site Location Considering Traffic Accident Characteristics in Mountainous Expressway
}

\author{
Rong Zhou ${ }^{a}$ and Yuanqing Wang ${ }^{b}$ \\ School of highway, Chang'an University, Xi'an 710064, China \\ azr_0521@foxmail.com, bwyq21@vip.sina.com
}

\begin{abstract}
With the focus on infrastructure construction to the mountainous expressway in China, it causes an intense discussion that how to guarantee the safety of operation. Due to the limitation of landform and physiognomy, there are many bridge and tunnel sections in mountainous expressway to rapidly pass through continuous vegetation area. However, when the traffic accidents cause the unsafe state of the mountainous fire, roads are often occupied by other vehicles. Accordingly, it is difficult that the external fire engines reach the position. Nevertheless, there is a need to place a fire station in a flat area of expressway side to emergency response. Thus, this paper takes the Xi'han expressway Qinling section as an example, and analyzes the characteristics of traffic accident based on the traffic accident data from 2009 to 2015 and introduces the rescue time model. Ultimately, evaluating the rationality of the location of Qinling Management fire station with site selection model which is established with considering traffic accidents. The result shows that serious and major accidents in mountainous areas are often caused by over speed driving, mechanical failure, ice, snow and fog conditions. In addition, the existing Qinling management site location is reasonable, the cumulative rescue travel time and the average travel time of per accident are 1252.411 minutes and 19.87 minutes respectively.
\end{abstract}

Keywords: Accident characteristics; fire station; mountainous expressway; location model.

\section{Introduction}

With the increasing length of expressway in China, traffic accident is increasing which happens on the expressways each year. At the end of 2017, the length of national highway is 4.77 million, and expressway is $136,500 \mathrm{~km}$ [1]. And as the focus of infrastructure construction shift to the west in China, the proportion of expressway in mountainous area is increasing, therefore, the probability of traffic accident and the risk of casualties and property loss are higher. So, it is very necessary and urgent to understand that what the characteristics of expressway traffic accident are and study that how to rescue and fire management when traffic accident happened in mountainous area.

Since 1960s, scholars have carried out studies about road traffic accidents. In developed countries such as Europe and America, the construction and operation of expressway are completed early, and the emergency rescue and rapid response special group is established to implement rescue and dispatch. A comparatively perfect accident rescue system is formed.

To established a series of perfect treatment methods from accident detection, accident rescue, accident clearing to traffic guidance, developed countries adopt advanced intelligent transportation technology applied to expressway $[2,3,4]$, such as computer technology, monitoring technology, TGIS technology, GPS technology and database technology, etc. In American, the Oak Ridge National Laboratory (ORNL) develops an emergency evacuation simulation system (OREMS) to simulate the evacuation path, evacuation time, etc. [5]

In China, Zhang Ying, Chongqing University, uses MapInfo to establish the digital map of the rescue system, and the improved Dijkstra algorithm is used to study the rescue time [6]. Ziliang Zhang, Jiangsu University, analyzes the rescue response delay, resource optimization configuration scheme, accident scene/report time and accident response time [7]. Fei Wang, Chongqing Jiaotong University, constructs the rescue time model and analyzed the joint rescue model of various rescue departments in expressway [8].

According the generalized traffic impedance, Xiaoyu Han, Xinwei Lu. etc. analyze the main factors affecting the rescue, and establish expressway emergency rescue route selection model, 
improved Floyd acceleration algorithm [9]. Xiaoguang Yang, Tongji University, expounds the necessity of establishing the expressway emergency rescue system from reality and theory [10].

To sum up, in the expressway's accident and fire management, although the relevant research on traffic accident emergency rescue has been relatively mature, most of the documents are only for general expressways, and there are relatively few researches on accident rescue in mountainous expressways.

\section{Data Source And Methods}

\subsection{Data Source}

According to the characteristics of the expressway in the mountainous area, selecting the Xi'han expressway in Shaanxi Province which has 56.232 kilometers in the area of Qinling Management as research object, as shown in red part of Fig.1. The data is real and effect, which Qinling Management is responsible for accident rescue and data record. These data include route information, tunnel information, firefighting data, accident data and road information.

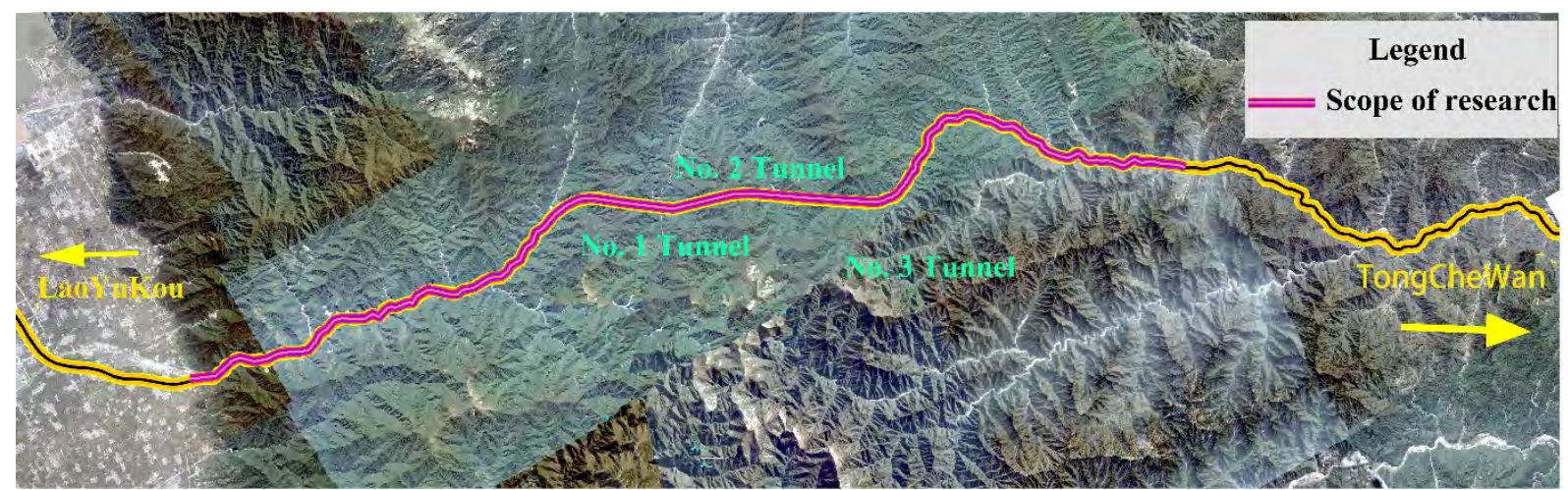

Fig.1 A map of the position of the research object

\subsection{Statistical Analysis of Accidents}

According to the study of Jianjun Wang, Junfeng Wang, etc. the main characteristics of ordinary expressway traffic accidents include the large proportion of vehicle tail bump and collision fixation. And the proportion of abnormal weather-induced accidents is about $30 \% \sim 40 \%$ [11]. However, compared with ordinary expressway, the road alignment of mountainous expressway is restricted by terrain, So the proportion of long downhill road, bridge and tunnel is large. Therefore, it is very important for the accident rescue to study the traffic accident characteristics of the mountainous expressway independently from the ordinary expressway. In this paper, the accident characteristics of mountainous expressway are studied by taking the research object as an example.

(1) Major accidents and serious accidents account for a considerable proportion. Major accidents and serious accidents are these events that causes more than 1 death or more than 3 persons serious injuries or more than 30,000-yuan property loss. According to the accident statistics, the percentage of serious accidents is decreasing each year, but the proportion is more than $10 \%$. It seriously affected the economic development. The accident statistic information of the Xi'han expressway in Qinling section is shown in table 1.

(2) Over speeding and mechanical failure are the main cause of the accident happened, such as brake pads failure, lighting is not bright, etc. This information is shown in Fig 2. Accidents due to overspeed account for $40 \%$ and mechanical failures occupy $37 \%$. The objective reason is that the proportion of large downhill sections is large, the longitudinal slop is large and long, and drivers' attention is highly concentrated for a long time. 
Table 1. The type distribution of accidents in the Xi'han expressway in Qinling section (unit: times)

\begin{tabular}{cccccccc}
\hline Year & 2009 & 2010 & 2011 & 2012 & 2013 & 2014 & 2015 \\
\hline Serious accident & 0 & 0 & 3 & 2 & 1 & 0 & 0 \\
Major accident & 8 & 6 & 7 & 12 & 4 & 1 & 2 \\
General accident & 2 & 3 & 4 & 2 & 2 & 4 & 4 \\
Minor accident & 18 & 7 & 15 & 17 & 23 & 9 & 10 \\
Total & 28 & 16 & 29 & 33 & 30 & 14 & 16 \\
Proportion of serious and Major accident & $29 \%$ & $38 \%$ & $34 \%$ & $42 \%$ & $17 \%$ & $7 \%$ & $13 \%$ \\
\hline
\end{tabular}

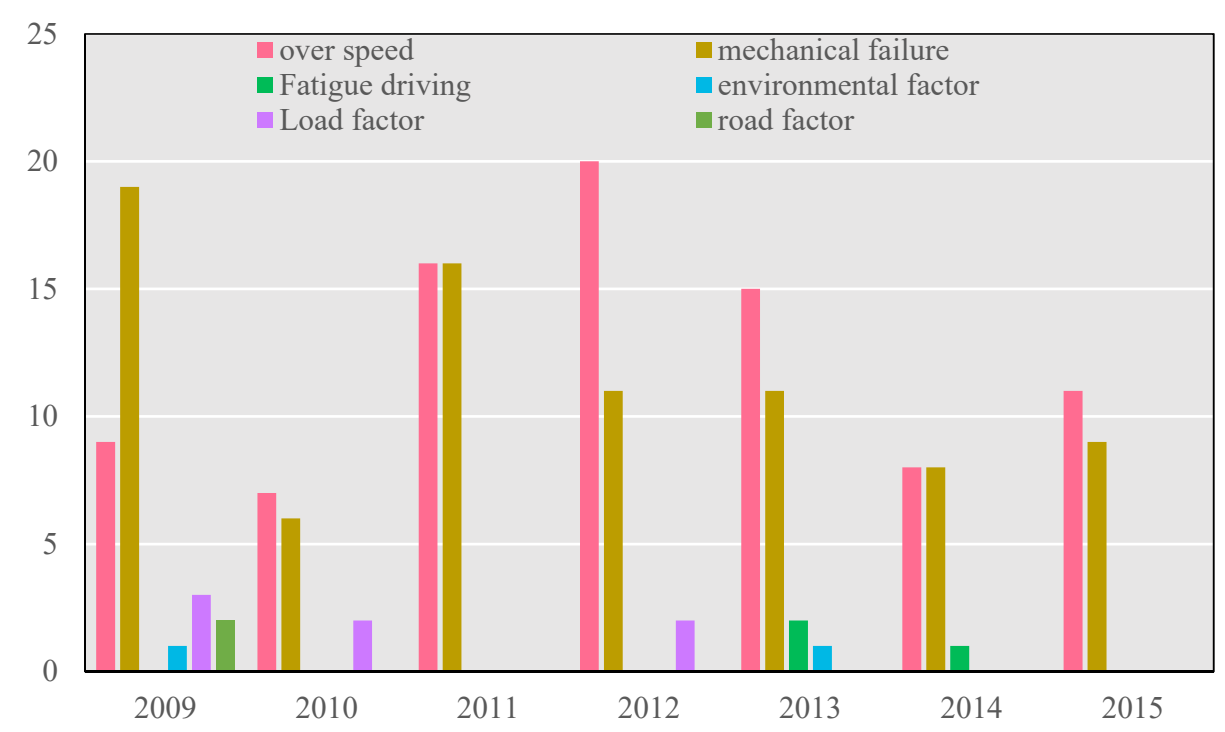

Fig.2 Accident cause statistics from 2009 to 2015 about research object (unit: times)

(3) The main accident patterns are vehicle rear-end accident and single-vehicle accident. From 2009 to 2015, there are 51 single-vehicle accidents, 91 rear-end accidents. And 78 injured and 33 dead, accounting for $42.5 \%$ of the total number of accidents and $49.7 \%$ of the total number of injuries. As shown in Fig.3, the number of death subject to normal distribution over the years, and reaching a peak 23 in 2012

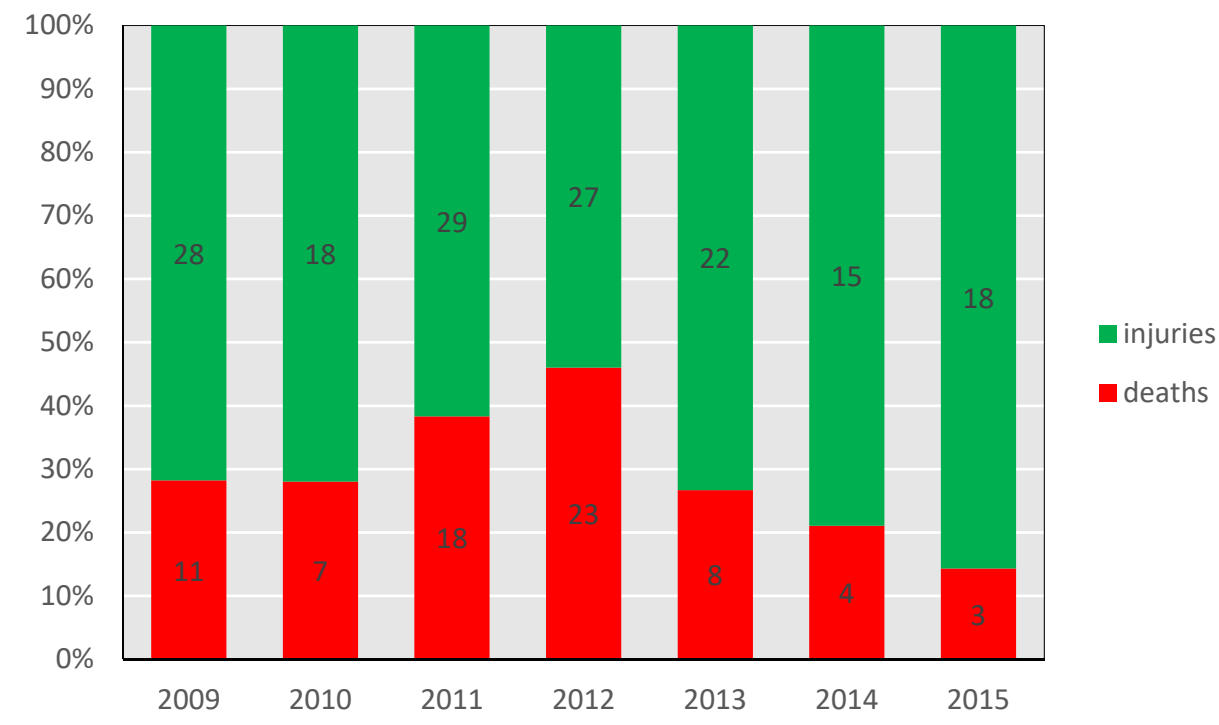

Fig.3 The proportion of casualties from 2009 to 2015

(4) The main vehicles for the accident are large trucks and cars. According to statistics, between 2009 and 2015, there are 89 accidents related to passenger cars and 122 accidents related to freight cars. The reason mainly has two points. Firstly, the Xi'han expressway is the main road connecting 
Sichuan province, and freight vehicles occupy a considerable proportion. The main reasons for the accidents of large trucks have poor braking effect, fatigue driving and overloading of goods. Secondly, because the cars occupy a large majority in the expressway, and the accidents occur because of the driver's safety experience and the lack of dangerous handling capacity.

(5) The abnormal weather has a serious impact. From 2013 to 2015, the number of accidents caused by ice, snow and fog are 295 , which accounts for $31.9 \%$ of the total number of accidents.

(6) Night accident rate is higher. The reason is that because of the high forest density in the mountainous area, tunnel groups, the driver's eyesight is frequently converted inside and outside the tunnel, so drivers more easily feel driving fatigue, so the mountainous expressway accident rate is higher.

The result shows that serious and major accidents in mountainous areas are often caused by over speeding, mechanical failure, ice, snow and fog.

\subsection{Modeling Site Location Model}

For expressway traffic accident, the emergency rescue is a complicated system process. Because the rescue forces from various departments, the rescue site is not controlled, and the impact of the accident may expand. Therefore, emergency rescue time refers to the duration of temporary reduction of capacity due to the occurrence of traffic accidents. It is composed of accident discovery or report time, reaction time, rescue and clean-up of the accident scene and time of traffic flow recovery. It is shown in Fig.4.

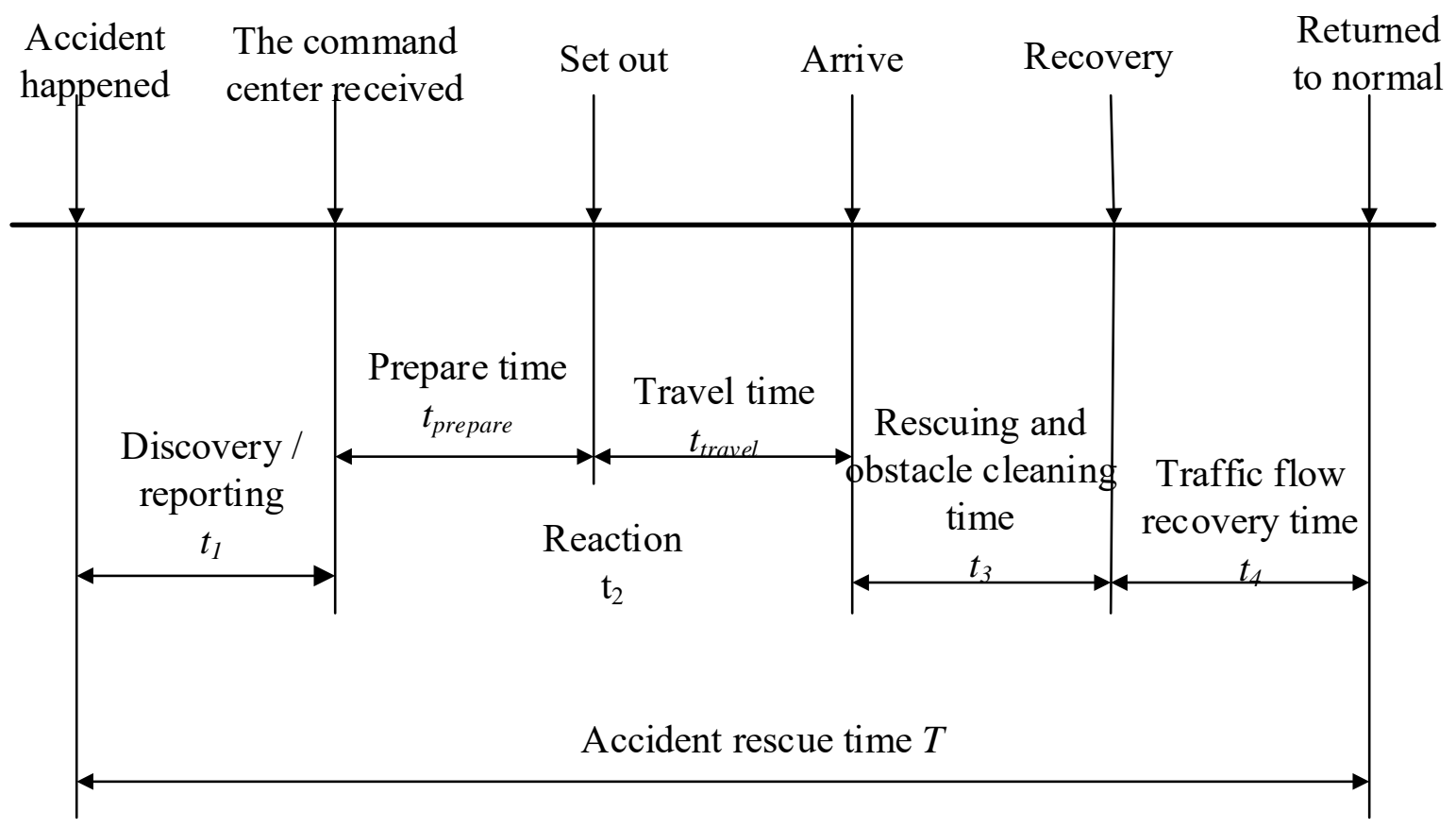

Fig. 4 Time structure of expressway traffic accident rescue [8]

According to Fig.4, the following rescue time model can be development:

$$
T=\alpha t_{1}+\beta t_{2}+\gamma t_{3}+\delta t_{4}+\varepsilon
$$

where, $T$ is the time of accident rescue; $t_{1}$ is the time of discovery and report; $t_{2}$ is the time of reaction; $t_{3}$ is on-site rescue time and $t_{4}$ is traffic flow recovery time; $\alpha, \beta, \gamma, \delta$ are correction factors; $\varepsilon$ is the random time of different level of accident, and $\epsilon \geq 0$.

Compared with general plain expressway, Mountainous expressway has little parallel with the road, it can only rely on the expressway itself to rescue. Fig. 5 shows the rescue principle. 


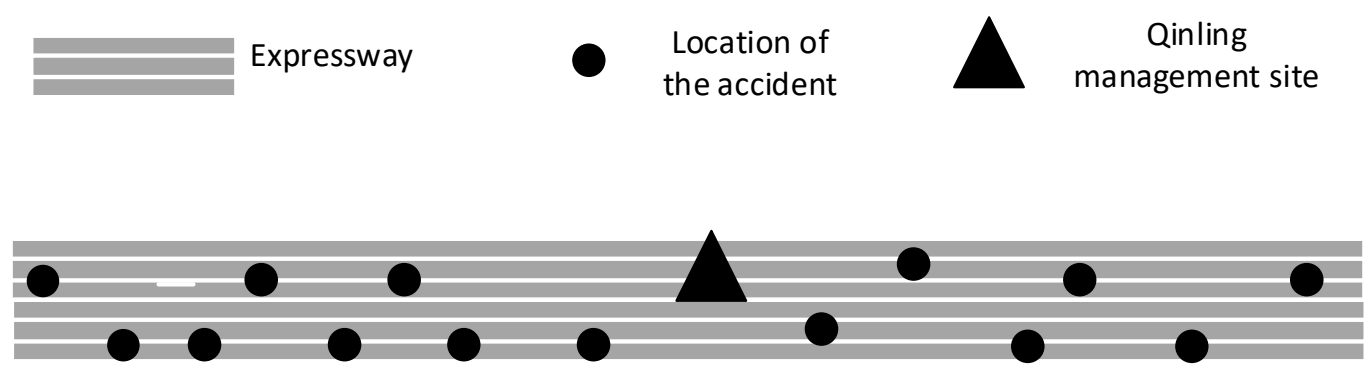

Fig.5 Simplified diagram of Accident rescue

Therefore, this paper has the following assumptions: (1) the model has only one path to choose from, no other alternative path; (2) regard the tunnel section, the site cannot be set in the tunnel section; (3) the model goal is the shortest time for summing time which arrive at each accident point, and each arrival of an accident point must return to manage, to reach the next accident point; (4) all accidents are equally important and do not distinguish the importance of accidents. Therefore, the site location model is established.

$$
\begin{gathered}
\min t_{2}=t_{\text {prepare }}+t_{\text {trip }}=t_{\text {prepare }}+\sum_{i} \sum_{j} L_{i} / V_{j} \times 60 \\
\text { s.t.: }\left\{\begin{array}{l}
L_{i}=\left|D_{i}-S\right| \\
L_{i} \geq 0, V_{j} \geq 0 \\
X_{1} \leq S \leq X_{2}
\end{array}\right.
\end{gathered}
$$

Where, $t_{2}$ is the time of reaction; $t_{\text {prepare }}$ is the prepare time; $t_{\text {trip }}$ is the travel time from management to accident point; $D_{i}, S, X_{1}, X_{2}$ are the accident $i$ mileage pile, management site location pile, the start piles and the end pile in research object.

\subsection{Application}

According to the Xi'han expressway accident statistics in Qinling section over past years, reflected on the map as shown in Fig.6. The accident concentrated in between the Lianglao tunnel and the Qinling No.3 tunnel, that is the mars red part. In addition, Zhifang tunnel, Qinling No.3 Tunnel, Shimen Tunnel, Babaoping Tunnel and other regional accidents are relatively concentrated, that is the light blue part of the map. And the rest of the road distribution are relatively dispersed.

In the case of running time only, and $\beta=1, \varepsilon=0$, travel speed is $80 \mathrm{~km} / \mathrm{h}$, table 2 is calculated. It shows that the rescue personnel arrive at accident scene in not more than 25 minutes after the accident, and the average is about 10 minutes. According to the related research, 2/3 of the serious injured are killed in 25 minutes, and if the injured do not get assistance within 30 minutes, the probability of death is threefold.

Table 2. Accident information in Qinling-section of Xi'han expressway (theoretical value)

\begin{tabular}{cccccccc}
\hline Year & 2009 & 2010 & 2011 & 2012 & 2013 & 2014 & 2015 \\
\hline Total mileage $(\mathrm{km})$ & 247.78 & 87.48 & 203.00 & 406.37 & 369.58 & 197.75 & 213.73 \\
Average & 10.32 & 9.72 & 15.62 & 12.70 & 13.20 & 14.13 & 12.57 \\
Average Arrival time(min) & 7.74 & 7.29 & 11.71 & 9.52 & 9.90 & 10.59 & 9.43 \\
Max reach time(min) & 15.66 & 11.72 & 25.41 & 21.88 & 24.21 & 22.41 & 25.26 \\
\hline
\end{tabular}

Mileage pile information in Qinling section about Xi'han expressway accident location is shown in table 4. And $X_{1}=1143.020, X_{2}=1199.252$. 
Table 3. Mileage pile information from 2009 to 2015 (unit: $\mathrm{km}$ )

\begin{tabular}{ccccccc}
\hline 2009 & 2010 & 2011 & 2012 & 2013 & 2014 & 2015 \\
\hline 1164.1 & 1153 & 1152.449 & 1155.5 & 1156.05 & 1179 & 1179 \\
1186 & 1153 & 1183.4 & 1164.9 & 1197.4 & 1153.6 & 1153.6 \\
1155.3 & 1162.33 & 1178 & 1165.2 & 1167.2 & 1153.3 & 1153.3 \\
1162 & 1155.05 & 1162.2 & 1151.7 & 1151.7 & 1195 & 1195 \\
1146 & 1155.3 & 1199 & 1167.4 & 1196.6 & 1153.3 & 1153.3 \\
1161.4 & 1156.99 & 1153.52 & 1179.4 & 1145.5 & 1160.5 & 1160.5 \\
1151.5 & 1149.5 & 1153.3 & 1146.4 & 1175.6 & 1180.8 & 1180.8 \\
1152.625 & 1173.2 & 1144.8 & 1186.5 & 1153.7 & 1188.4 & 1188.4 \\
1168.483 & 1156.4 & 1146.5 & 1152.6 & 1175.7 & 1187.6 & 1187.6 \\
\hline
\end{tabular}

When calculating the travel time, the rescue speed is simplified to $80 \mathrm{~km} / \mathrm{h}$. The result of LINGO software is 1160.6 . That is to say, a fire station should be set at 1160.600 , so that the shortest time to arrive at the rescue team is $1249.268 \mathrm{~min}$. The location is shown in Fig.6 blue dot. But the position of fire station is actually located inside the Qinling No.1 tunnel (1158.752 - 1164.896), therefore, in order to make the site location more reasonable, the Qinling No.1 tunnel should be excluded and recalculated. The recalculation result is 1158.752 , and the cumulative travel time is $1252.411 \mathrm{~min}$, as shown in Fig.6 pink dot. It locates between the Zhuque tunnel and the Qinling No.1 tunnel

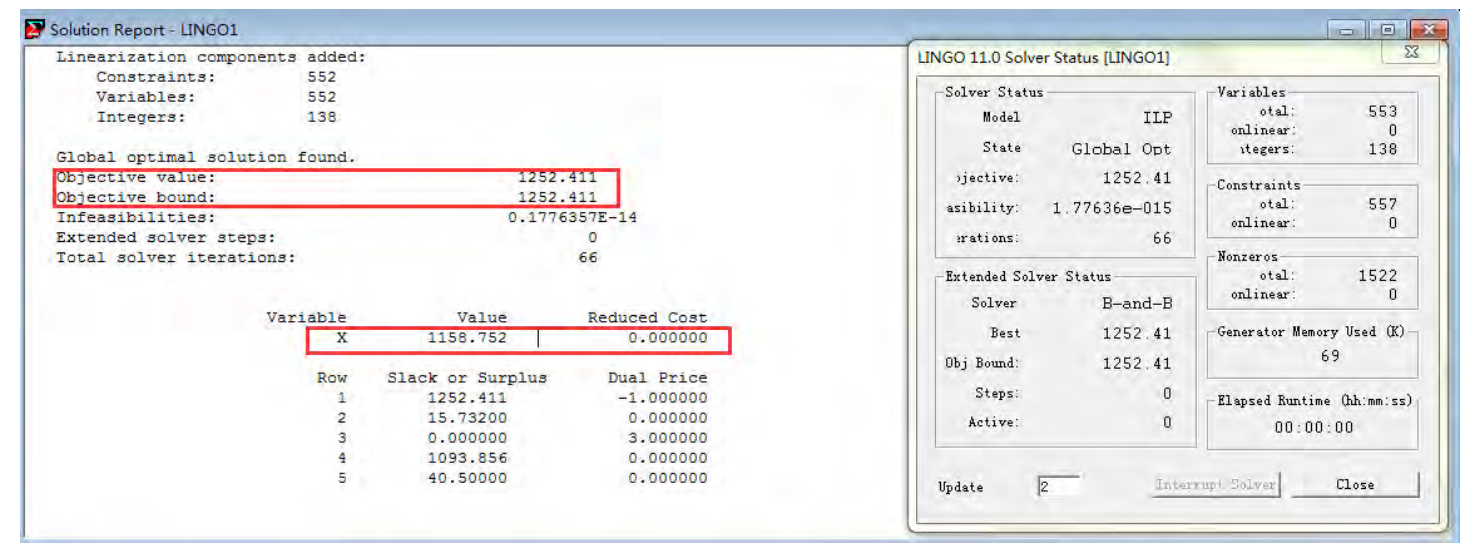

Fig.6 Final result of model calculation

The fire station of Qinling Mountains management station is located in the pile number K1165+358, that is between tunnel No. 1 and No. 2 tunnel. It is small brown dots in Fig.7. The distance from the optimal location is $4.758 \mathrm{~km}$, and the theoretical travel time $(80 \mathrm{~km} / \mathrm{h})$ is $3.57 \mathrm{~min}$. In addition, the fire station is not only a service area for the driver to stay and rest, but also is a beautiful scenery which attract many visitors. Therefore, the current fire station set up is reasonable with the above factors.

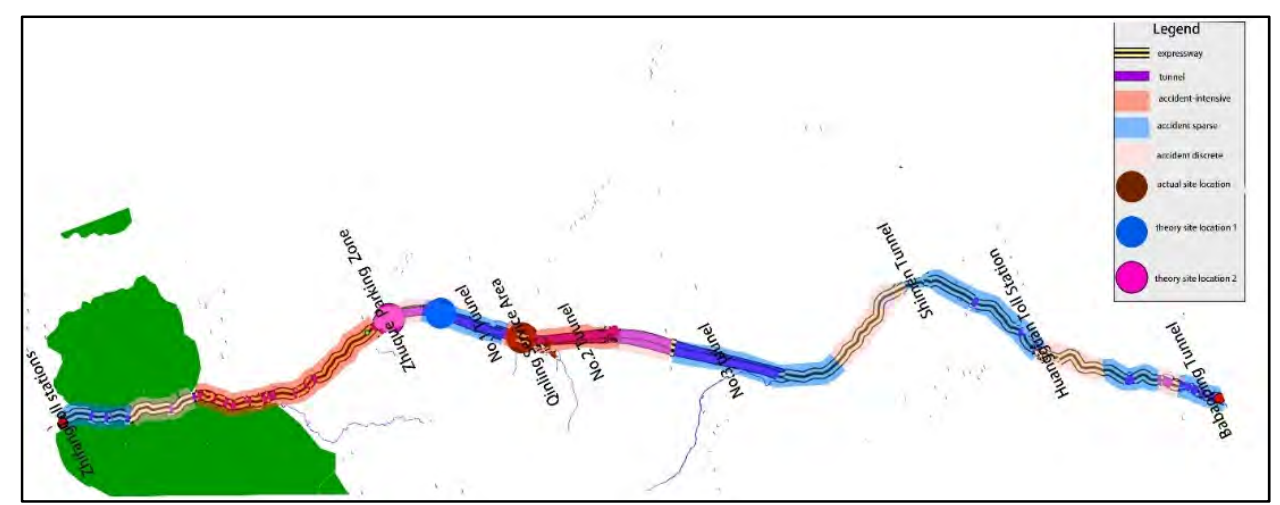

Fig.7 Accident distribution Pattern in Qinling section of Xi'han expressway 


\section{Summary}

This paper discusses the accident characteristics about mountainous expressway, analyzes the composition of rescue time, establishes the site location model. It indicates that traffic accidents in mountainous expressway happen mainly due to over speeding, mechanical failure and bad weather, etc. Therefore, the operation management need to strengthen the speeding control, forced cooling pool transformation, special weather warning and notices and other measures to ensure travel safety. According to the site location model to evaluate the existing management position with comprehensive considering of travel time, economic benefits and setting conditions, the existing site is reasonable and feasible.

Although this paper has obtained some research results, the current research does not take the preparation time, the rescue resources, the accident grade, etc. consideration to the model, this is the thesis shortcoming, is also the next research direction.

\section{References}

[1]. Information on: http://data.stats.gov.cn/easyquery.htm?cn=C01\&zb=Aogo3\&sj=2015.

[2]. Mattsson B, Juas B. The importance of the time factor in fire and rescue service operations in Sweden. Accident; analysis and prevention, Vol29(1997) No.6: p.849-857.

[3]. Lei W, Jiang C H, Peng X, et al. Design on expressway emergency rescue management system based on the GIS-T.[C]// International Conference on Transportation Engineering. Chengdu, 2009: p1957-1962.

[4]. Kowtanapanich W, Tanaboriboon Y, Charnkol T. A Prototype of The Gis-Based Traffic Accident Database System. Journal of the Eastern Asia Society for Transportation Studies, Vol.7(2007) No.1: p.2757-2769.

[5]. U S. Department of Homeland Security Sea Power, Vol.8 (2004), No.6: p.319-330.

[6]. Yin Zhang, Research and Realization of Accident Emergency Rescue System Based on Optimal Planning, Master, Chongqing University, China, 2005, p.8-42.

[7]. Ziliang Zhang, Research on the Centralized Expressway Emergency Rescue Command System Based on GIS, Master, Jiangsu University, China, 2007: p.1-15.

[8]. Fei Wang, Study on Emergency Rescue Time Model of Freeway Traffic Accident and Layout of Rescue Site, Master, Chongqing Jiaotong University, 2008: p.25-34.

[9]. Xiaoyu Han, Xinwei Lu, Qunqi Wu, Path Model for Route Selection for Expressway Emergency Rescue, Journal of Chang'an University (natural science edition), Vol.33 (2013), No.5: p.86-92.

[10]. Xiaoguang Yang, Research on Expressway Emergency Rescue Management System Based on ITS, Shanghai Highways, Vol.1 (2002), No.1: p.4-8.

[11]. Jianjun Wang, Junfeng Wang, Mingtao Bi, Characteristics of Traffic Accidents on Highway and Expressway, Journal of Chang'an University (natural science edition): p.66-69.

[12]. Peihong Wang, Study on Urban Traffic Incident Emergency Management System and its Theoretical Problems, Master, Tianjin University, China, 2005: p.34-45. 